\title{
The application of service marketing strategy in hotel management
}

\section{Zhu Renpeng}

Department of Foreign Languages, Xijing University, Xi'an, Shaanxi,710123

Keywords: service marketing strategy; hotel management; application; research

\begin{abstract}
In the current fierce market competition, enterprises want to develop steadily and expand the market scale constantly to explore the innovative ways of enterprise development. Especially under the influence of economic globalization, the competition between the same types of enterprises is becoming increasingly fierce, and the product quality, product usage, product prices are not much different circumstances, businesses only improve the quality of service from the aspects, to seize the initiative. This paper expounds the related contents of service marketing strategy, and emphatically expounds the specific application of service marketing strategy in hotel management, hoping to improve the level of hotel management.
\end{abstract}

In recent years, due to the rapid development of China's tourism industry, it has also brought the flourishing development of the hotel industry. Also, because of the more severe economic situation, the hotel management needs to be constantly reformed. All kinds of marketing strategies are widely used in hotel management, so that the marketing management of the hotel is gradually normalized and quality. Hotels in order to enhance their competitiveness, they pay more attention to service quality. They hope to get customer satisfaction through high quality services and create a good image for hotels. This article is to explore the application of service marketing strategy in hotel management [1].

\section{Introduction}

In China, Algus Hotel management is not exactly defined. It is only a way of managing hotels by operating the managers of hotels in order to get economic benefits and attract customers. However, with the development of China's tourism industry, the management of the hotel has also gained a certain development. The current hotel management refers to the purpose of maximizing the economic benefits of the hotel. The management process of the optimal allocation of various resources under the requirements of the conditions of laws and regulations and the requirements of the objective law of the market. In recent years, with the rapid development of China's economy, the competition in the hospitality industry is becoming increasingly fierce. The quality of hotel management directly affects whether the hotel can get the advantage in the market competition. Therefore, the hotel management of the implementation of high standards, it is necessary to grasp the whole hotel under the rule of market economy, the rational allocation of resources, at the same time according to the changes of external environment to develop effective marketing strategies to attract a large number of customers, so as to let the hotel stand out [2].

The hotel industry itself belongs to the scope of service industry, and marketing strategy refers to service marketing, which can get a good impression from customers through high-quality service and win good reputation. This is not only a way to get new visitors, but also to keep old customers and establish long - term relationships. Although the hotel industry is mainly to provide accommodation services, but the quality of the service can get customers' trust and good feeling. Especially for consumers, high quality service can move consumers' heart and improve customer satisfaction [3].

From the perspective of consumers, the needs of every consumer are varied and varied. No one hotel can satisfy all consumers' requirements. But all the customers have a unified standard, which is the pursuit of the quality of the hotel service. Therefore, for hotels, each hotel must make accurate positioning according to its own business and business characteristics, and find out its main 
consumer groups. At the same time, according to the characteristics of each type of consumer group, we make a special service marketing strategy, which will help to gain the competitive advantage. Specifically, the following points are included: first, the accurate positioning of the consumer group, that is, the hotel in the formulation of service marketing strategy to determine the target consumer groups. For example, the orientation of the hotel consumer groups are high-end business people, so when the service will be the high-end atmosphere on the grade, to meet the psychological characteristics and service business requirement, at the same time, service personnel should have a certain level of English, which is conducive to communication between the customer and the. If the hotel locates the consumer group is young people, then in service personnel's clothing and language should be younger, the tidal current, lets the person feel fresh and interesting. In a word, the hotel must set their own environmental and comprehensive level, to provide services to consumers, and to ensure that the service can meet consumers' habits and basic interests and hobbies, so as to improve hotel service quality, in order to improve customer satisfaction. Second, after deciding the target consumer group, the hotel needs to combine the hotel's own situation to set up an image for the consumer group, which is also an important basis for determining the service marketing strategy. That is to say, what kind of impression does a hotel want to leave behind its customers' mind? What's the height to achieve? It requires hotels to find the key points for reform, which is beneficial for consumers to recognize the image of the hotel. For example, hotel accommodation, decoration style, service content and so on are the key to improve the quality of the hotel and create a good image for the hotel. Only when the hotel is impressed with consumers, consumers will choose to continue to stay next time, which is also an effective way to improve the hotel's economic benefits. Third, make an effective marketing plan. When the hotel is targeted at the target consumer group and the accurate hotel location, the hotel also needs to develop effective marketing programs, such as online advertising, media advertising, celebrity endorsement, preferential activities, etc., to develop the market for the hotel. We should enhance the visibility and convey the hotel information to the target consumer group, so that we can be well known and let consumers explore and try the heart of the hotel. Only in this way can we further promote the further development of the hotel [4].

\section{The application of service marketing strategy in hotel management}

From products and services, the hotel can be from two aspects, the first aspect is the portfolio of services, the hotel needs according to the different consumers and changing the different period of development, the market demand for different products combination, provide better service to customers. In the process of product service, it is necessary to form a series of products by combining the breadth, length, depth and density of the product. Breadth refers to the number of various types of products that the hotel has, such as accommodation service, room service, catering service and so on. Length refers to the different services included in each product, such as takeout services, meal service and so on. Depth refers to the related types of services included in each product, such as tea service and dessert service in catering services. The second aspect is the overall product service. This is from the hotel's overall product concept, including the core products, form products and extended products. The core product refers to the hotel in order to meet the needs of customers to the maximum extent, in the design of products, starting from the core of customer demand for products and services, to find the accurate market positioning for the hotel, and then carry out various marketing activities, in order to meet customer service activities. The form product is the external packing form of the hotel product, which includes the entity product and the invisible service. Customers can directly understand the core culture of the hotel products through the form of products. And to a large extent, the most expensive aspect of the consumer is the form product. In the process of marketing, hotels can attract customers' attention by making various new and different forms of products to stimulate customers' desire for purchase. The extended product refers to the additional value and interest provided by the hotel for the customer. For example, quality, price, psychology and so on can make the customer feel different value. In addition to the service that the product can provide to the satisfaction of the customer, the importance of the service talent is self-evident. In today's era, business competition is becoming increasingly fierce. The hotel 
itself is a highly mobile company, and the cultivation of a high-quality service personnel is not a simple matter. Hotels often take a lot of time and material resources to develop a qualified service person. However, because of the low promotion space and low salary level, many high quality service talents have been lost. Therefore, for the hotel, in order to carry out the service marketing strategy in depth, we must pay attention to the training and reserve of the service personnel. First of all, hotels should culture their service personnel according to their unique hotel culture, so that they can feel the charm of hotel culture and cultivate their sense of loyalty and belonging. So they will be more willing to honest and sincere for the hotel service. Secondly, the hotel should adjust the salary structure, pay attention to the use of incentive mechanism, train and retain excellent quality service personnel. Finally, the hotel regularly or unregularly trains the service staff to improve their service attitude and service skills [5].

To provide service to the customer, the hotel should be according to their actual situation and the inner needs of consumers to determine the specific, but not to blindly or highlight the strength in the service and other hotel competition, do so easily lead to high cost, and is not conducive to improve the quality of service. And we want to really improve customer satisfaction and do a good job of service. It should be as follows: first, hotels need to conduct market research work first. This work is to understand consumers' service needs, that is, in order to grasp the psychology of consumers. In the process of research, we should pay attention to the accurate understanding of customer needs. If we know the wrong amount of words, we will not only waste resources, but also be difficult to achieve effective results. Second, do the same type of hotel market research work, there is a saying that good: "to know ourselves and know yourself", understand the service content of opponent, also has very important significance to improve the hotel service quality. Third, comprehensive analysis of data information. After mastering the specific data information, it is necessary to analyze and summarize it, and to find out the service items to be improved on this basis and improve it. Fourth, the service quality control standards are formulated, and the quality of the staff is evaluated regularly to ensure that the service can be carried out in depth [6].

In hotel management, the implementation of service marketing strategy depends not only on service products, but also on service personnel. That is to say, we need to rely on certain technical facilities and technical conditions to improve the service quality of hotels. Therefore, hotels should formulate clear and clear service standards, such as service personnel civilized manners, rules and regulations formulation, service personnel dress requirements formulation, breach of service standard punishment measures and so on. The formulation of these contents is helpful to improve the quality of service workers, and because of their service level and bonus performance, it can give service staff enough attention. In addition, the hotel should also improve its own service facilities to provide a good service environment for customers. For example, when consumers wait to check in or spend time on credit card, in order to make consumers more comfortable in waiting time, the hotel can set comfortable seats in the hall, arrange drinks, biscuits, magazines and newspapers on the tea table to meet customer's needs. For example, for a variety of hotel room price should be clearly marked, to avoid the customer again and again to ask, such as price standard rooms and is equipped with service packages, deluxe rooms and is equipped with service packages, members and non members enjoy the discount price and some service packages and so on, which is conducive to the customer choice the most suitable service in the shortest time. At the same time, hotel facilities should be changed regularly to create a service environment for customers.

China well as an old saying goes: "no man". In the process of hotel management, there will inevitably be some mistakes. But in the face of mistakes, managers should not be evaded or refused to take responsibility. Instead, they should apply the service recovery strategy in the first time, so as to save the influence of bad actions on the hotel image. First of all, in the process of service remedies, when it is found that the service error is not at the time, we should be brave to take responsibility in the first time, and must never be shirking. Accept customer complaints and criticisms in a sincere way. At the same time, when solving the problem of improper service, we should communicate with and communicate with customers in time, so that customers can understand that the hotel attaches importance to this problem and is actively solving this problem. 
To a certain extent, this can make the customer get a psychological balance. When the problem is solved, the customer will be informed of the results. If the compensation is not procrastinating, it is necessary to make up for the reparation immediately. And the problem that needs to be paid attention to in the application service remedial strategy is the mastery of the time of remedies. In order to be able to make remedial actions within the first time, a hotel needs to establish an effective mechanism to track and identify service failures. First of all, hotels can set up special departments and personnel to take charge of the work. Their main job is to listen to customers' opinions and understand their customers' dissatisfaction, so as to identify potential service failures. There is also a need for them to summarize experience and solutions for these finding problems, and provide regular service recovery training for service workers, such as service recovery skills, service recovery attitude, performance adaptability and so on. This kind of training is helpful for the front-line service staff to recover in the first time when they encounter unexpected situations, and also help to recover the bad effects.

\section{Conclusion}

In a word, in the current market competition, the competition among the hotel industry is becoming more and more intense, and the hotels of the same type, the same price and the same style are everywhere. The hotel wants to survive and develop in fierce competition, and implement service marketing strategy and improve service quality, which is undoubtedly an effective way to improve hotel competitiveness. Therefore, in the process of hotel management, we should pay attention to the application of service marketing strategy, enhance the concept of hotel services, and get more consumers' recognition, so as to achieve the purpose of improving the economic benefits of hotels.

\section{References}

[1] Bungkwon Bok, Francis Buttle. Hotel marketing strategy and the theory of reasoned action[J]. International Journal of Contemporary Hospitality Management, 1996, volume 8(3):5-10.

[2] Riveros S J, Berné M C. [Application of marketing strategies for the management of public hospitals from the viewpoint of the staff members]. [J]. Revista Médica De Chile, 2006, 134(3):353-60.

[3] Kosic K, Lazic L, Stojanovic V. Application of Contemporary Marketing Strategy in Development of Rural Tourism Destinations- Case Study of Vojvodina [J]. Tourism \& Hospitality Management, 2010.

[4] Hsu Y L, Ting Y S. THE APPLICATION OF E-MARKETING STRATEGIES IN U.S. HOSPITALITY INDUSTRY[J]. 2013.

[5] Zengin B, Akyol C. Actual Marketing Strategies of the Hotel Management: Example of Sakarya - Otel İşletmelerinin Uyguladıkları Güncel Pazarlama Stratejileri: Sakarya Örneği[C]// 3. International International Conference of Business Students - 3. Uluslararası İşletme Öğrencileri Kongresi. 2016.

[6] Suess D, Trieloff L, Bremner J C. Marketing Strategy Lifecycle Management, US20150262257[P]. 2015. 